\title{
Crossing Timelines
}

\section{Main research topics in the histories of eCAADe and SIGraDi}

\author{
David Sperling ${ }^{1}$, Simone Helena Tanoue Vizioli ${ }^{2}$, \\ Gabriel Braulio Botasso ${ }^{3}$, Mateus Segnini Tiberti ${ }^{4}$, \\ Eduardo Felipe Zambom Santana ${ }^{5}$, \\ Brianda de Oliveira Ordonho Sigolo 6 \\ 1,2,3,4,6 Institute of Architecture and Urbanism, University of São Paulo ${ }^{5}$ Institute of \\ Mathematics and Statistics, University of São Paulo \\ ${ }^{1}$ sperling@sc.usp.br ${ }^{2,4,6}\{$ simonehtv|mateus.tiberti|brianda\}@usp.br \\ ${ }^{3,5}$ \{gabrielbotassousp|ezambomsantana\}@gmail.com
}

\begin{abstract}
Being in tune with the joint eCAADe and SIGraDi conference, this paper systematizes and analyzes data related to the set of papers presented in the history of the conferences of both societies. Which paths traced from eCAADe and SIGraDi brought us to the "architecture in the age of the fourth industrial revolution"? This paper describes a bibliometric study focused on eCCADe and SIGraDi papers from 2003 to 2018 retrieved from CumInCad by using an open source software developed by the team for this research. The most used keywords and most cited authors, cross-citations between societies and time series about this data were synthesized, recovering part of the histories of these societies. Some similarities and differences between them are pointed out allowing to understand their past for better drawing their future.
\end{abstract}

Keywords: CAAD, History, Bibliometrics, Cumincad, eCAADe, SIGraDi

\begin{abstract}
INTRODUCTION
As Walter Benjamin (1969 [1935]) wrote about the art in "the age of mechanical reproduction", every mode of production also generates human sensibilities that are related to it. Since Benjamin's work, the expression " $\mathrm{X}$ in the age of $\mathrm{Y}$ " has been used to distinguish some alterations in the modes of production and reception related to architecture and the arts in the face of technological, cultural, and economic transformations (Eisenman, 1994; Davis, 1995; Gumbrecht \& Marrinan, 2003; Frampton, 2005, among others).
\end{abstract}

Therefore, "architecture in the age of the fourth industrial revolution" is not only inserted within the lineage of references to the title of Benjamin's celebrated essay but also induces the investigation of sensibilities that have shaped this new condition of architecture. In this sense, a historiography of the concepts that make up an epistemological context becomes a relevant way for the understanding of this very context.

The introduction and evolution of computing in architecture in just over half a century is been accom- 
panied by still recent historiography of this process. Authors have already focused on the emergence of architectural theories (Rocha, 2004), the evolution of the publications themes (Koutamanis, 2005) and the archeology of scientific conferences in the field (Celani \& Veloso, 2015), among other topics.

Being in tune with the joint eCAADe and SIGraDi conference, this paper systematizes and analyzes data related to the set of papers presented in the history of the conferences of both societies, which have been, respectively, since 1983 and 1997, the main scientific forums on CAAD in Europe and Ibero-America.

Which paths traced from eCAADe and SIGraDi brought us to the "architecture in the age of the fourth industrial revolution"? Further on, are there similarities/differences in relation to the thematic approaches between both sisters societies conferences? What are the main topics covered by the papers throughout this period? Are there temporal asynchronies in approaching these topics? Are the main references cited in the papers coincidental and/or express local specificities?

\section{METHODS}

Bibliometrics was used for this study, seeking for metric indicators derived from scientific publications to verify research trends, using the eCAADe and SIGraDi papers published in CumlnCAD digital library between 2003-2018 as a sample universe. The choice of this period of time is justified below. Pritchard (1969, p. 349) defined bibliometrics as " [...] the application of mathematics and statistical methods to books and other media of communication", Fairthorne (1969, p. 319) paraphrased as "quantitative treatment of the properties of recorded discourse and behavior appertaining to it."

To retrieve the bibliometrics data from eCAADe and SIGraDi was developed an open-source software in Python, named WSB (Figure 1), that reads the HTML code of CumInCAD, available on $<$ https://github.com/ezambomsantana/web_scraping_bibliometrics $>$. In this site, it is possible to generate a page with all the metadata from all the arti- cles for a conference and a year range. After reading this data, we created tables with the keywords and references of all the papers. Then, we could group and aggregate the data creating different information about the conferences such as the most cited keywords and authors by year.

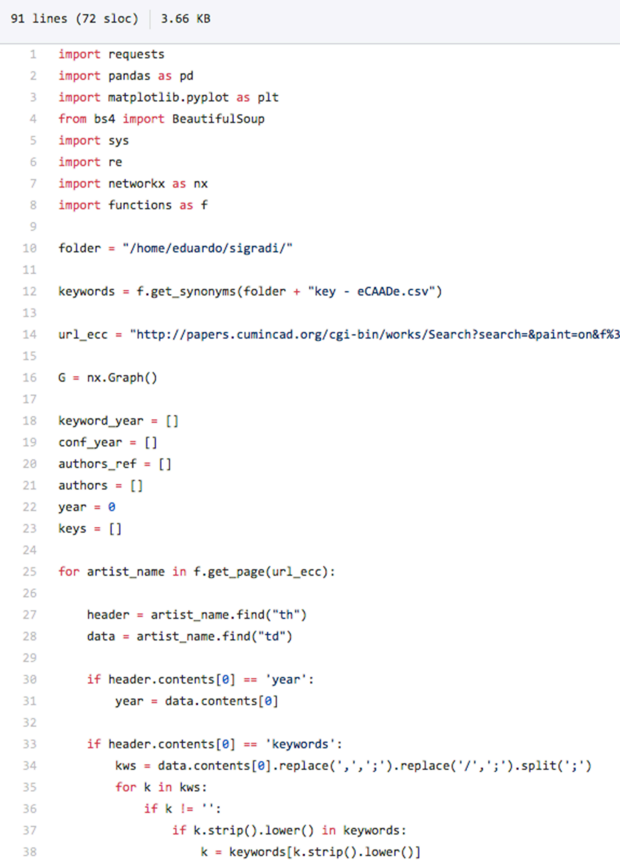

CumlnCad is an acronym for CUMulative INdex of CAD created in 1998 as a repository of scientific information in the field of CAAD (Martens, Turk, 2000; 2003), upgraded to free access in 2015 . Its main goal is "(1) to build a 'collective memory' of scientific publications from conference proceedings of CAAD-associations; and (2) to make this memory unconditionally accessible to the scientific community as a web-based bibliographic repository of works" (Cerovsek \& Martens, 2016: 485). In previous work, Cerovsek and Martens (2004) have already presented an extended review of this repository showing its po-
Figure 1

Detail of the WSB code 
Table 1

Number of Papers from eCAADe and SIGraDi per year (2003-2018) tential as a resource to the researches in the field of CAAD. They analyzed the chronological distribution of CumlnCad references; frequency, distribution, age, year-to-year distribution between citations; distribution of citations per number of authors. Some examples of author-citation networks and a list of the 25 most cited authors by the 6399 records retrieved in the repository in 2004 were presented as well.

A comparative study focused on data from papers of specific societies retrieved from CumlnCad has not yet performed. From the 14386 entries found in CumlnCad (June 2018), we retrieved data from 4009 papers, which corresponds to $28 \%$ of the total entries. This sample corresponds to 2095 papers from eCAADe and 1914 papers from SIGraDi.

The methodology of our research is structured by the following steps: 1) data entry of the general themes of the annual congresses of each sister society (eCAADe / SIGraDi); 2) collecting keywords from all papers; 3 ) data tabulation of the 10 most used keywords by each sister society papers per year; 4) selection of papers that use the prevailing keywords in each sister society per year; 5 ) data entry of bibliographic references most used by papers selected in each sister society per year (at least three citations); 6) pre-analysis of the data obtained by society and by year (keywords and bibliographic references); 7) crossing of collected data (eCAADe x SIGraDi); 8) generation of diagrams and timelines with the data of each society and by crossing data; 9) analysis of data.

One limitation of the methodology is some missing data in CumlnCad. For SIGraDi, from the 2313 papers from the period 1998-2018, 30\% do not have the keywords or the references in the metadata. This problem was minimized in the last years, as from 2009 to 2018 , only $15 \%$ of the papers do not have the keywords or the references. Regarding eCAADe, there are also some missing data. From the $2528 \mathrm{pa}-$ pers, $15 \%$ of them do not have the keywords, and $8 \%$ do not have the references in the metadata. About SIGraDi, the templates from 1998 to 2002 and 2005 have not keywords or the keywords have not metadata. About eCAADe, the year 2002 has not metadata for the keywords.

The period initially defined to run this study was 1998-2018, considering the first year of SIGraDi papers available on CuminCad. But, due to these inconsistencies, the period of the study was changed to 2003-2018. Even for this period, some observations should be done. SIGraDi 2005 was not considered in the study because there is no metadata of keywords. SIGraDi 2004 was not considered in the references study because there is no metadata about them. eCAADe 2015 was not considered from the references study because there is no metadata of keywords in Cumincad and the software we developed needs them in the system to retrieve the references. In this case, keywords were collected by hand for allowing the most completeness of the study. Table 1 shows the number of papers from eCAADe and SIGraDi per year in Cumincad.

\begin{tabular}{ccc}
\hline Year & eCAADe & SIGraDi \\
\hline 2003 & 104 & 131 \\
2004 & 82 & 126 \\
2005 & 102 & 140 \\
2006 & 134 & 96 \\
2007 & 116 & 88 \\
2008 & 118 & 23 \\
2009 & 107 & 142 \\
2010 & 96 & 103 \\
2011 & 112 & 125 \\
2012 & 158 & 151 \\
2013 & 152 & 129 \\
2014 & 132 & 135 \\
2015 & 155 & 121 \\
2016 & 146 & 149 \\
2017 & 169 & 101 \\
2018 & 212 & 154 \\
Total & $\mathbf{2 0 9 5}$ & $\mathbf{1 9 1 4}$ \\
\hline
\end{tabular}

\section{RESULTS AND DISCUSSION}

The results of the study are systematized below in three topics: 1) conferences themes; 2) top ten keywords; 3 ) most referred authors and cross-citations. 


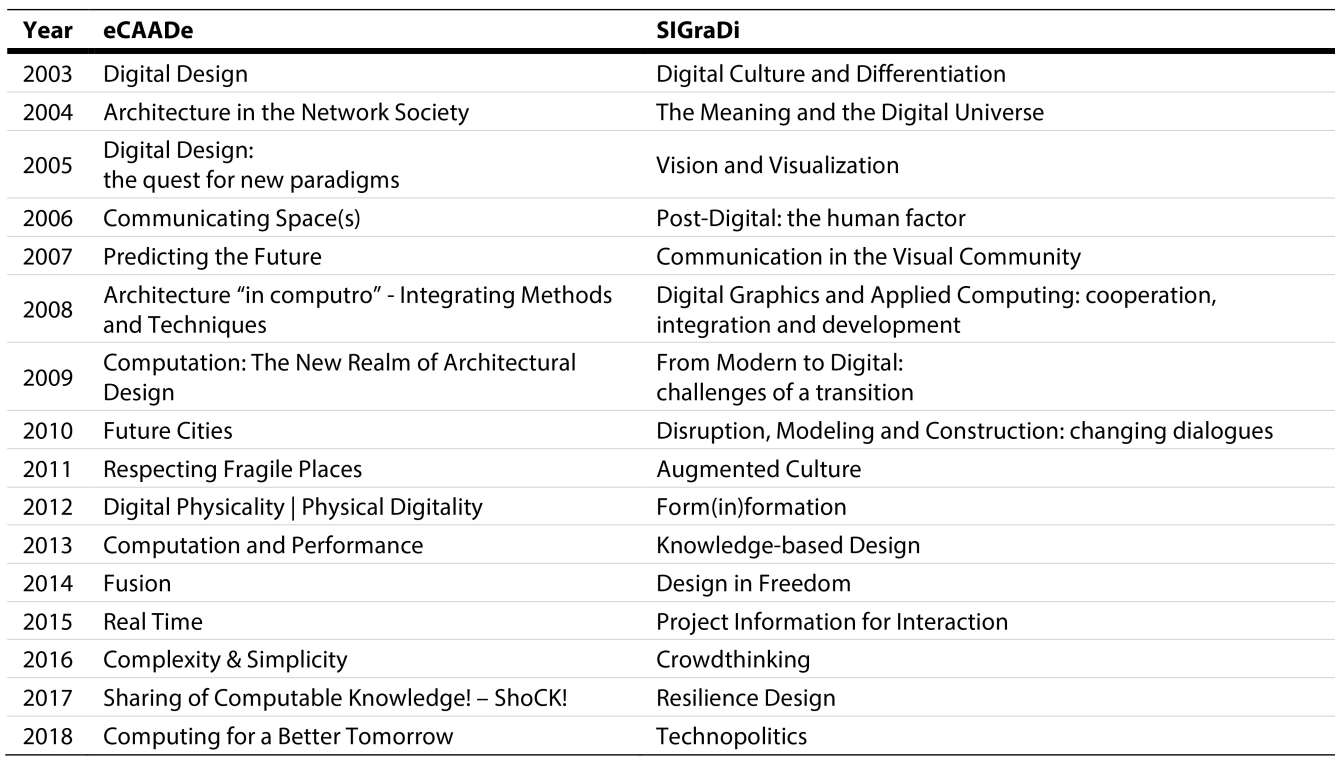

Table 2

Conferences

Themes

(2003-2018)

\section{Conferences Themes}

The eCAADe and SIGraDi conferences use to have main themes from which they intend to converge knowledge interchange and discussions on CAAD and relate topics. Table 2 shows the conferences' themes of both societies for the 2003-2018 period. A deep analysis of them is not an object of this paper, but in general, the themes are compound by concepts, statements or actions related to the expanded field of CAAD. These themes seem to indicate aspects of global order, linked to the globalized digital context, and aspects of local order, linked to specific forms of insertion in the global debate.

\section{Top Ten Keywords}

Using the WSB open-source software developed for this study, we found 8574 entries for keywords in papers of eCAADe conferences and 5888 entries for keywords in SIGraDi. As the template of SIGraDi 2005 has not keywords, the corresponding papers, their data were not retrieved. As keywords have recurrence,

the number of keywords are 5058 and 3327 respectively. This sample shows that eCCADe sample is 1.52 the SIGraDi sample. After the keywords in each paper were tabulated, and the ten most frequently used keywords in the entire period and in each year were highlighted. Table 3 shows the frequencies of the top ten eCAADe and SIGraDi keywords for the entire period.

\begin{tabular}{lcc}
\hline $\begin{array}{l}\text { Data retrieved in } \\
\text { CumlnCad }\end{array}$ & eCAADe & SIGraDi \\
\hline $\begin{array}{l}\text { Number of papers } \\
\begin{array}{l}\text { Keywords in the } \\
\text { sample }\end{array}\end{array}$ & 2095 & 1914 \\
$\begin{array}{l}\text { Total of keyword } \\
\text { entries in the sample }\end{array}$ & 8558 & 3327 \\
\hline * The SIGraDi 2005 template has not keywords. \\
\hline
\end{tabular}

The eCAADe and SIGraDi shared 6 keywords from their top ten: parametric design, digital fabrication, bim, virtual reality, shape grammar and design pro-
Table 3

Keywords

Occurrence in eCAADe and SIGraDi (2003-2018) 
cess. Still in the top ten, the other eCAADe keywords were: urban design, generative design, collaborative design and simulation; for SIGraDi the other keywords are: heritage, architectural design, interaction and cad.

The general results show that the top ten keywords had a big frequency in the whole sample of keywords of both societies, making a total of $46.8 \%$ of the keywords used in eCAADe and $36.2 \%$ of keywords used in SIGraDi.

Considering the use of keywords throughout the years, there are some interesting dynamics to point out. The keywords design fabrication and parametric design became strong terms in both societies from 2006, even if the last one appeared before in eCAADe in 2003. Together with BIM, that appeared among the top ten keywords from 2007 in both societies and generative design appeared in eCAADe from 2006, these keywords indicate some of the main research topics in more than a decade. Simultaneously to the strengthening of these topics, 3D modeling and animation started to be outside of the top ten keywords for both societies in 2009. The correlation of these facts exposes a relevant turning point to the research in CAAD from those years.

Another interval to highlight is 2013-2016 when computational design (2013), robotic fabrication and 3D printing (2015) began to be inside the top ten in eCAADe, and virtual reality (2016) reappeared in both societies after being between the top ten between 2003 and 2010. In the period, collaborative design (2013) and education (2015) left the list of top ten keywords of eCAADe and design process (2015) left the same list for both societies. These alterations, if maintained, could indicate another relevant shift to the research in CAAD in the near future.

Both societies shared emphases on the keywords design process (2003-2015) and shape grammar (2005-2018) throughout the period. For the eCCADe side there are emphases on collaborative design (2003-2013), generative design (2006-2018), computational design (2013-2018), urban design (2010-2018). For the SIGraDi side were found emphases on the use of digital tools for heritage (20042018), interaction (2011-2016). Other keywords used appeared in SIGraDi conferences had not prevalence in more than two years, indicating a distribution of occurrences of many keywords. A timeline was drawn to turn visible these dynamics among research topics (Figure 2). The whole image is available at $<$ https://drive.google.com/file/d/1w2mtoZ2iDZUJ7sU1j1yulDPUbtGV1o3/view?usp=sharing $>$ (Top of the image).

\section{Most Referred Authors and Cross-citations}

From the lists of top five keywords per year in each society, the papers of the sample that mentioned at least one of these keywords had their references retrieved. The top ten authors cited in eCAADe and SIGraDi for that keywords are listed in Table 5. Taking into account the period from 2003 to 2018, eCAADe and SIGraDi share 5 among the 10 most referred authors in their conferences for those keywords. While in eCCADe the top ten referred authors are from the
Figure 2

Detail of the timeline of main research topics in eCAADe and SIGraDi according the years (2003-2018)

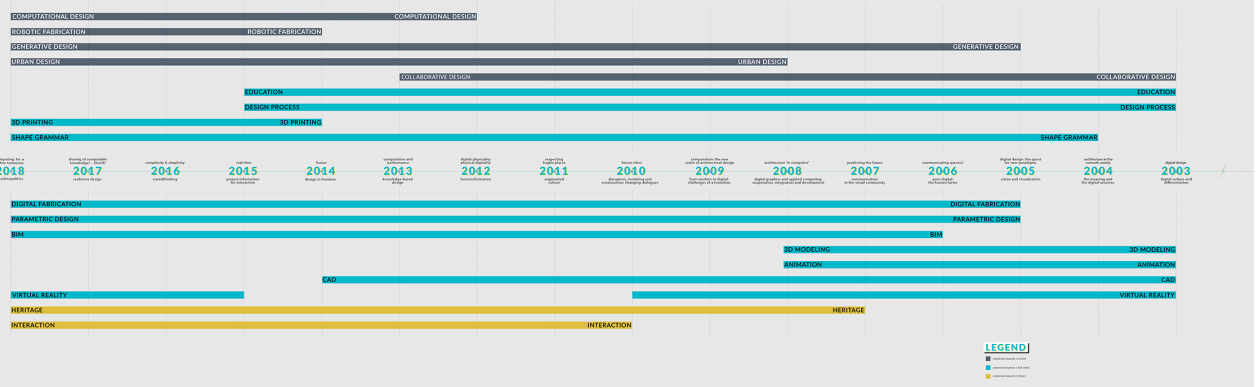




\begin{tabular}{|c|c|c|c|c|c|}
\hline \multicolumn{3}{|c|}{$\begin{array}{c}\text { eCAADe } \\
\text { Number of papers: } 2095\left(^{*}\right)\end{array}$} & \multicolumn{3}{|c|}{$\begin{array}{c}\text { SIGraDi } \\
\text { Number of papers: } 1774\left(^{*}\right)\end{array}$} \\
\hline Keywords & $\mathbf{n}$ & $\%$ & Keywords & $\mathbf{n}$ & $\%$ \\
\hline parametric design & 184 & 8.8 & parametric design & 137 & 7.7 \\
\hline digital fabrication & 135 & 6.4 & digital fabrication & 134 & 7.6 \\
\hline bim & 117 & 5.6 & bim & 79 & 4.5 \\
\hline urban design & 92 & 4.4 & heritage & 58 & 3.3 \\
\hline collaborative design & 83 & 4.0 & shape grammar & 40 & 2.3 \\
\hline shape grammar & 80 & 3.8 & virtual reality & 37 & 2.1 \\
\hline design process & 57 & 2.7 & interaction & 32 & 1.8 \\
\hline simulation & 57 & 2.7 & cad & 28 & 1.6 \\
\hline Total & 981 & 46.8 & Total & 639 & 36.2 \\
\hline
\end{tabular}

* Obs. (1) The keywords "architecture" and "design" were considered as qualifiers and were excluded of the sample. (2) Papers from SIGraDi 2005 were excluded due to the lack of keywords.

\begin{tabular}{|c|c|c|c|}
\hline \multicolumn{2}{|c|}{$\begin{array}{c}\text { eCAADe } \\
\text { Total of references: } 262\end{array}$} & \multicolumn{2}{|c|}{ SIGraDi } \\
\hline Authors & Citation frequencies & Authors & Citation frequencies \\
\hline stiny, $\mathrm{g}$ & 76 & eastman, c. m. & 35 \\
\hline fioravanti a. & 44 & duarte, j.p. & 31 \\
\hline menges, a. & 33 & herr, c. m. & 20 \\
\hline mitchell, w.j. & 33 & kohler, m. & 18 \\
\hline beirão, j. & 32 & gramazio,f. & 17 \\
\hline kohler, m. & 32 & sacks, r. & 17 \\
\hline gramazio,f. & 31 & borda, a. & 16 \\
\hline
\end{tabular}

Table 4

Frequencies of eCAADe and SIGraDi Keywords (2003-2018)

Table 5

Top ten authors cited in eCAADe and SIGraDi for the top five keywords (2003-2018)
Global North, in SIGraDi only two of the most referred authors are from the Global South, Gabriela Celani and Adriane Borda. Other significant difference is the frequency with which each reference was mentioned in these two societies. Among the top ten authors, Branko Kolarevic is the only one who is more cited in SIGraDi than in eCCADe, while the other authors have more citation frequency in eCCADe (See Table 5).

In the next step, authors referred at least three times for a keyword per year of each society were retrieved. In the eCAADe, 262 authors were mentioned at least 3 times, while in the SIGraDi, 115 authors followed the same criterion. From them, only 20 authors are coincident in papers of both societies.
Among the other authors cited there are a recurrence of regional and local citations that will be subject of a future study.

Another analysis performed was focused on topics that had authors cited at least 3 times in both societies in the same year, looking for similarities and differences between main topics of both societies (See table 6). The keywords found under this criterion were: digital fabrication, parametric design, BIM, virtual reality and urban design. Then, the top ten authors for each keyword were selected. Among them, there were authors referred to in papers related to several keywords. José Pinto Duarte was cited for digital fabrication, parametric design and urban de- 
Table 6

Top ten authors for main topics -

keywords with authors cited at least 3 times in both societies in the same year (2003-2018)

Table 7

Number of

Cross-citations between papers from eCAADe and SIGraDi

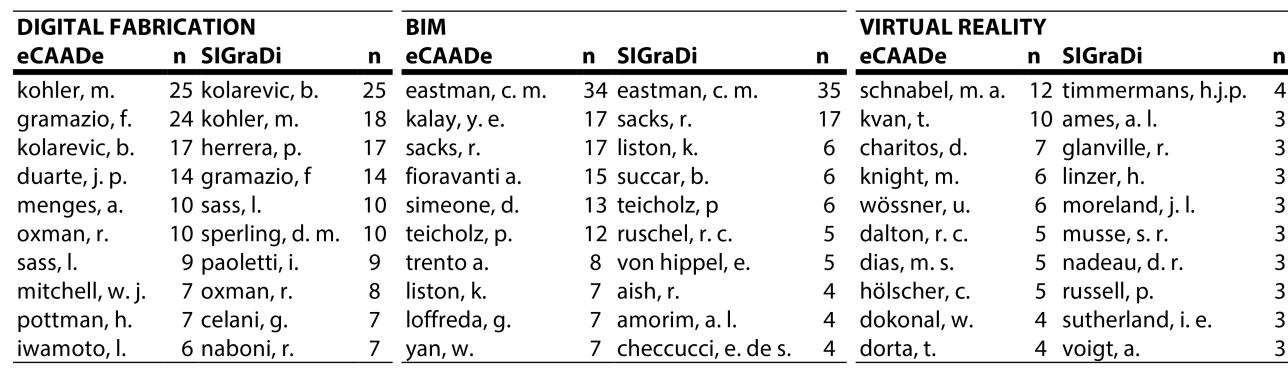

PARAMETRIC DESIGN URBAN DESIGN

\begin{tabular}{|c|c|c|c|c|c|c|c|}
\hline CAADe & $\mathbf{n}$ & SIGraDi & $\mathbf{n}$ & eCAADe & $\mathbf{n}$ & SIGraDi & n \\
\hline menges, a. & & kolarevic, b. & 19 & duarte, j. & & duarte, j.p. & 5 \\
\hline dbury, $r$. & 17 & oxman, r. & 14 & beirão, j. & 16 & schmitt g. & 5 \\
\hline$y, g$ & 14 & borda, a. & 10 & stouffs, r. & 10 & nameed, w. & 4 \\
\hline man, r. & 12 & celani, g. & 9 & schmitt, g. & 9 & kobayashi, y. & 4 \\
\hline nsel, m. & 10 & hillier, b. & 9 & waddell, $p$. & 9 & müller, p. & 3 \\
\hline larte, j. p. & 9 & woodbury, r. & 9 & gil, j. & 7 & & \\
\hline nssen, p. & 9 & duarte, j. p. & 7 & van gool, I. & 7 & & \\
\hline larevic, b. & 9 & mitchell, w. j. & 6 & zupancic, t. & 7 & & \\
\hline tman, h. & 8 & sass, I. & 6 & montenegro, $\mathrm{n}$. & 6 & & \\
\hline ouffs, r. & 8 & terzidis, $\mathrm{k}$. & 6 & haegler, s. & 5 & & \\
\hline
\end{tabular}
stouffs, r.

6 haegler, s.

\begin{tabular}{ccc}
\hline Year & $\begin{array}{c}\text { eCAADe papers } \\
\text { in SIGraDi } \\
\text { papers }\end{array}$ & $\begin{array}{c}\text { SIGraDi papers } \\
\text { in eCAADe } \\
\text { papers }\end{array}$ \\
\hline 2003 & 8 & 8 \\
2004 & 0 & 4 \\
2005 & 12 & 8 \\
2006 & 4 & 7 \\
2007 & 12 & 6 \\
2008 & 14 & 7 \\
2009 & 22 & 4 \\
2010 & 10 & 7 \\
2011 & 7 & 3 \\
2012 & 6 & 8 \\
2013 & 16 & 6 \\
2014 & 28 & 5 \\
2015 & 16 & 8 \\
2016 & 27 & 3 \\
2017 & 12 & 5 \\
2018 & 34 & 8 \\
Total & $\mathbf{2 2 8}$ & $\mathbf{1 0 4}$ \\
\hline
\end{tabular}


sign. Branko Kolarevic, Achim Menges, Rivka Oxman, Lawrence Sass, William Mitchell and Helmut Pottman were cited for digital fabrication and parametric design. Rudi Stouffs was cited for parametric design and urban design. The other authors were associated with only one keyword.

Some similarities with the citations for the top five keywords were found here. While in eCCADe the top ten referred authors are from the Global North, in SIGraDi only seven of the most referred authors are from the Global South, Pablo Herrera, Gabriela Celani and David Sperling for digital fabrication, Adriane Borda and Gabriela Celani for parametric design, Regina Ruschel, Arivaldo Amorim and Érica Checcuci for BIM. Gabriela Celani is the only author of SIGraDi most cited for two keywords in SIGraDi itself.

Looking for other interrelations between both societies, a cross-citation study was performed. The results indicate that eCCADe papers are more cited in SIGraDi than the opposite (See table 7). One among other inferences that can be made for this difference is that most of the SIGraDi papers were written in Spanish and Portuguese. On the other hand, there were a significant number of intra-region citations, that is, eCAADe papers were cited by other eCAADe papers, and SIGraDi papers were cited by other SIGraDi papers. An extensive network of authors and their origins, languages and citations will be subject for a further study.

\section{Cross-citations}

In order to synthesize much of this paper's data, another timeline was drawn to allow visualizing information as conference themes, top five keywords, authors with at least three mentions per year, the number of citations per author along the years (Figure 3 ). The whole image is available at <https://drive.google.com/file/d/1w2mtoZ2iDZU-

J7sU1j1yulDPUbtGV1o3/view?usp=sharing $>$ (Bottom of the image).

\section{CONCLUSION AND OUTLOOK}

The study carried out from the most cited keywords and most referenced authors captured processes of consolidation and change of research topics. This methodology can not point to the first occurrences in relation to time series but captures these processes when they incorporate a larger critical mass, as shown in the timelines (Figures 1 and 2). These timelines show how consolidation processes and disruptive moments are produced collectively by an extensive community of researchers, which even exceeds the two societies.

The WSB open-source software developed proved to be an excellent tool for retrieving information from Cumincad metadata. New increments are being considered to create an interface for displaying the data in the form of timelines and networks.

The data analyzed show differences and similarities between eCAADe and SIGraDi. The former clearly shows a stage of maturity, while the later shows a process of growth and strengthening of its performance. The growth of a group of authors most cited in recent years in the SIGraDi conferences, as well as the similarity of the main research topics with eCAADe, show its insertion in a global context of research. A contribution to a greater connection between the productions of both societies, and to a greater impact of the papers presented in SIGraDi and made available by CumlnCad, would be the adoption of English. While some research topics appeared simultaneously among the top ten keywords in both societies, such as digital fabrication and parametric design, others are still far from this level as computational design and robotic fabrication. Factors not treated in this study, economic ones and others relative to the context of the civil construction, are decisive to understand this challenging scenario for innovation.

It is expected that the visualization and analysis of data extracted from papers presented in the eCAADe and SIGraDi between 2003 and 2008 could contribute to the mutual understanding about part of the history of emphasis given to research by the 
Figure 3

Detail of the timeline of top five keywords and most referred authors per year in eCCADe and SIGraDi

(2003-2018).

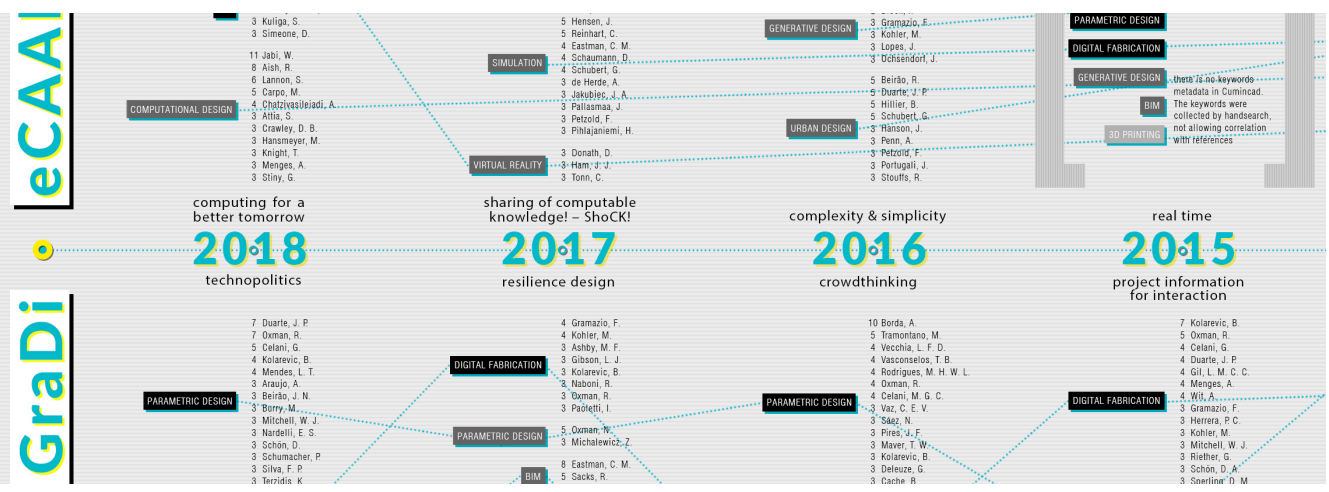

participants of these sister societies, which significantly contributed to the scientific knowledge in the CAAD area over the last two decades. Returning to the introduction of this paper, we believe that the way perception is organized depends not only on human nature and the historical context, as Walter Benjamin stated. From a contemporary view anchored in Gilles Deleuze (1995 [1968]), the perception of the present time is only shaped by the understanding of different coexistences that make it up.

\section{ACKNOWLEDGMENTS}

The authors thank the CumlnCad for the free access to its database and CNPq for the Fellowship of Research Productivity (n. 304266/2016/7).

\section{REFERENCES}

Benjamin, W 1969, 'The Work of Art in the Age of Mechanical Reproduction', in ARENDT, H (eds) 1969, Illuminations: Essays and reflections, Schocken Books, New York, pp. 217-251

Burdick, A, Drucker, J, Lunenfeld, P, Presner, T and Schnapp, J 2016, Digital_Humanities, The MIT Press, Cambridge

Celani, G and Veloso, P 2015 'CAAD conferences: A brief history', Computer-Aided Architectural Design: The Next City - New Technologies and the Future of the Built Environment: 16th International Conference, CAAD Futures 2015, São Paulo, Brazil, pp. 47-58
Cerovsek, T and Martens, B 2016 'CumlnCAD 2.0: A Redesigned Scalable Cloud Deployment - Towards higher impact with openness and novel features', Proceedings of the 34 th eCAADe Conference, Oulu, pp. 485-492

Cerovsek, T and Martens, B 2004, 'On the Extended Use of Citations in CAAD', in Van Leeuwen, JP and Timmermans, HJP (eds) 2004, Developments in Design \& Decision Support Systems in Architecture and Urban Planning, Eindhoven University of Technology, Eindhoven, pp. 1-17

Davis, D 1995, 'The Work of Art in the Age of Digital Reproduction (An Evolving Thesis: 1991-1995)', Leonardo, 28(5), pp. 381-386

Deleuze, G 1995, Difference and Repetition, Columbia University Press, New York

Eisenman, P 1994, 'Visions unfolding: architecture in the age of electronic media', Ars Electronica Festival 1994 Catalogue: Intelligent Ambiente - Intelligent Environment, 1

Fairthorne, R 1969, 'Empirical hyperbolic distributions (Bradford-Zipf-Mandelbrot) for bibliometric description and prediction', Journal of Documentation, 25(4), pp. 319-343

Frampton, K 2005, 'Introduction: The Work of Architecture in the Age of Commodification', in Saunders, W (eds) 2005, Commodification and Spectacle in Architecture: A Harvard Design Magazine Reader, University of Minnesota Press, Minneapolis, pp. ix-xviii

Gumbrecht, HU and Marrinan, M (eds) 2003, Mapping Benjamin. The Work of Art in the Digital Age, Stanford University Press, Redwood City

Koutamanis, A 2005 'A Biased History of CAAD', Digital Design: The Quest for New Paradigms, 23nd eCAADe 
Conference Proceedings, Lisbon, pp. 629-637

Lima, M 2011, Visual complexity: mapping patterns of information, Princeton Architectural Press, New York

Martens, B 2004 'Cumincad Hacks', Proceedings of the 8th Iberoamerican Congress of Digital Graphics, Porto Alegre, pp. 487-492

Martens, B and Turk, Z 1999 'Working Experiences with a Cumulative Index on CAD: "CUMINCAD", Architectural Computing from Turing to 2000, eCAADe Conference Proceedings, Liverpool, pp. 327-333

Martens, B and Turk, Z 2003, 'Cumulative Index of CAAD: Current Status and Future Directions', International Journal of Architectural Computing, 1(2), pp. 219-231

Pritchard, A 1969, 'Statistical bibliography or bibliometrics?', Journal of Documentation, 25(4), pp. 348-349

Rocha, AJM 2004, Architecture theory, 1960-1980: emergence of a Computational Perspective, Ph.D. Thesis, MIT 